\title{
NOTICE
}

\section{Request for Errata in Star Catalogues of Position}

$T^{\mathrm{H}}$ HE United States Naval Observatory and the Yale University Observatory have been collaborating on the preparation of IBM punched cards of Zone Catalogues and certain other widely used catalogues. In the course of this undertaking numerous errors in the published catalogues have been discovered. A compilation of corrections is to be published soon after the completion of the card catalogues.

The following are among the catalogues completed or in preparation:

Yale Zone Catalogues, Trans. Yale Univ. Obs., Vols. 11-14, 16-27.

Catalogue of Bright Stars (Schlesinger and Jenkins, 1940).

General Catalogue of Trigonometric Stellar Parallaxes (Jenkins, 1952).

AGK2, Vols. 1-15.

Cape Photographic Catalogues

Zones $-30^{\circ}$ to $-40^{\circ}$, Ann. Cape Obs., Vols. 17, 18.

Zone $-40^{\circ}$ to $-52^{\circ}$, Cape Zone Catalogue of 20843 stars, equinox 1900 (London, 1923). Proper motions of the stars in the Zone Catalogue of 1900.

Zones $-52^{\circ}$ to $-64^{\circ}$, Ann. Cape Obs., Vols. 19-20.

N30, Astron. Papers Am. Ephemeris and Nautical Almanac, Vol. 13, Part 3, 1952.

In order that the compilation of corrections may be as complete as possible, the authors request that other users of these catalogues report any errors they have found to the undersigned.

DORRIT HOFFLEIT Yale University Observatory

Box 2023, Yale Station

New Haven, Connecticut

\section{NEW BOOKS RECEIVED}

Annuaire pour l'An 1961 (with Supplement for 1962), published by the Bureau of Longitudes, Paris. Price, paper back $40 \mathrm{NF}$, Composition $45 \mathrm{NF}$.

Although containing in abbreviated form the principal astronomical tables of the standard national ephemerides, this useful work has, in addition, an extraordinary variety of miscellaneous information, including, for example, calendars ranging from the French Revolutionary to the Saints Days for 1961, and from Coptic to Cambodian. Geodesy, refraction, tides, terrestrial magnetism, minor planets, vital statistics - all these and very much more are to be found in notes, tables, and graphs. Excellent review articles on such subjects as meteors, comets, stellar parallax, novae and supernovae, artificial satellites, and a large French telescope make up more than half the book. Use for reference, fun for browsing, very well indexed. (In French.)

Astronomischer Jahresbericht, 58. Band, published by the Astronomisches Rechen-Institut in Heidelberg. Price, 60-DM.

Fifty-eighth annual volume of the unique and indispensable reference summary, covering in highly organized and indexed form all astronomical literature published in 1958.

The Scientific A merican Book of Projects for the Amateur Scientist, by C. L. Strong. Published by Simon and Schuster, New York. Price \$5.95.

The first section, on astronomy, contains nine articles of interest to teachers and astronomical gadgeteers. Observational astronomers may find useful the detailed description of a transistorized drive and of the Leighton electronic seeing compensator.

A ussergalaktische Sternsysteme und Struktur der Welt im Grossen, by Henrich Vogt. Published by the Akademische Verlagsgesellschaft, Leipzig, 1960. Price DM-20. (Volume 32 of Probleme der Kosmischen Physik.)

Short review monograph on galaxies. A 70-page summary of some of the better-known observational material is followed by succinct semiquantitative accounts of Newtonian, relativistic, kinematical, steady-state, and variation-of-constants cosmologies. (In German.) 